\title{
Variable Region of 16s rRNA is Essential For the Identification of Group 1 Mosquito-Pathogenic Strains of Lysinibacillus
}

\author{
Ajeet Kumar Mohanty ${ }^{1}$, Sandeep Garg ${ }^{2}$, Kulvir Dhindsa ${ }^{3}$ and Ashwani Kumar ${ }^{1 *}$ \\ ${ }^{1}$ National Institute of Malaria Research (ICMR), India \\ ${ }^{2}$ Department of Microbiology, Goa University, India \\ ${ }^{3}$ Department of Zoology, D. A. V College, India
}

Submission: November 27, 2016; Published: January 31, 2017

*Corresponding author: Ashwani Kumar, M.Sc., Ph D, Scientist 'F' \& Officer-in-Charge, National Institute of Malaria Research (ICMR), Field Unit, DHS Building, Campal, Panaji, Goa- 403001, India, Tel: +91 832 2222444; Email: ashwani7@gmail.com

\begin{abstract}
A study was carried out to characterize and identify the potential mosquito-pathogenic bacilli strains isolated from the soil samples obtained from various locations in Goa, India. Six isolates were characterized morphologically, biochemically and phylogentically. Phylogenetic relationships of these strains were determined based on comparison of the 16S rRNA sequences with that of the closest Lysinibacillus species obtained from nucleotide database. Their mosquitocidal abilities were confirmed by bioassay and presence of genes responsible for pathogenicity and toxin production. Molecular characterization by partial sequencing of $16 \mathrm{~S}$ rRNA gene has confirmed their identity as Lysinibacillus sp. Group 1.

Comparison of the 16S rRNA sequences with that of the five groups of "Bacillus sphaericus like organisms", re-designated off lately as Lysinibacillus, revealed that a variable region of $695 \mathrm{bp}$ and hypervariable region of $22 \mathrm{bp}$ were highly conserved among these five groups. These isolates were found effective against Culex quinquefasciatus larvae with $\mathrm{LC}_{50}$ values ranging from 0.018 to $0.58 \mathrm{ppm}$. The PCR amplification also showed the presence of $\operatorname{bin} A, \operatorname{bin} B$ binary genes and $m t x 1, m t x 2, m t \times 3$ mosquitocidal genes. Larvicidal activity against $C u l e x$ quinquefasciatus appeared related with expression of binary toxins. These strains were found more potent than the commercial strain and hence could be formulated for controlling Culex species transmitters of Japanese encephalitis and filariasis.
\end{abstract}

Keywords: Biocontrol agent; Binary toxins; Hypervariable; Lysinibacillus strains; 16S rRNA gene

Abbreviations: Btx: Binary Toxins; Mtx: Mosquitocidal Toxins; HV: Hyper Variable; NJ: Neighbor Joining; NYSM: Nutrient Yeast Sporulating Medium

\section{Introduction}

Some strains of "Bacillus sphaericus like organisms" are toxic to dipteran larvae and used operationally for control of mosquito-borne diseases. These micro-organisms are aerobic, spore-forming bacteria producing spherical or oval endospores and contain endotoxins responsible for the killing of mosquito larvae [1]. The larvicidal strains contain two types of insecticidal toxins viz. binary and mosquitocidal. The binary toxins (Btx) are spore associated toxins produced during sporulation phase and form crystals in the mother cell. The crystal comprises of two toxic proteins with molecular weights of about $42 \mathrm{kDa}$ (binA) and $51 \mathrm{kDa}$ (binB). Both proteins are required in equal amounts for larval toxicity $[2,3]$.
In contrast, mosquitocidal toxins (Mtx) are produced during vegetative stage. There are three Mtx toxins (Mtx1, Mtx2 and Mtx3) that have been identified in some mosquitocidal strains [4-6]. Interestingly, Mtx proteins are degraded by extracellular proteases which are produced when the cell growth reaches sporulation phase [7]. Highly toxic strains are known to produce both Btx and Mtx toxins, while other strains synthesize either of them [8]. Krych et al. [9] on the basis of DNA-DNA homology demonstrated that Bacillus sphaericus is a conglomerate of 5 distinct homology groups. Group I represents Bacillus sphaericus sensu stricto, while Group II consists of two subgroups, IIA \& IIB. All mosquito pathogenic strains are placed in subgroup IIA. Group IIB consists of non-pathogenic Bacillus fusiformis. 
Alexander \& Priest [10] attempted to use phenotypic features to separate these groups. The toxic strains of Group IIA produce ribosomal RNA gene restriction patterns which are different from Group IIB and non-toxic Bacillus sphaericus sensu stricto [11]. De muro \& Priest [12] developed an oligonucleotide probe based on specific region of $16 \mathrm{~S}$ rDNA which differentiates Group IIA from other DNA homology groups. However, Jhanz et al. [13] showed that this probe also hybridizes with non-toxic strains. RAPD and repetitive primer amplified polymorphic DNA analysis showed close relatedness among mosquito pathogenic strains belonging to homology group IIA $[14,15]$. Nakamura [16] redistributed Bacillus sphaericus-like organism based on 16S rRNA gene sequence into seven distinct clusters. In this schema, mosquitocidal and few non-mosquitocidal strains were clustered in Group 1 which corresponded to Krych Group IIA and closely linked to Group 2 representing Krych Group IIB named as Bacillus fusiformis.

Group 1 to 4 of Bacillus sphaericus like organisms were re-designated as new genus Lysinibacillus on the basis of the presence of lysine in the cell wall [17]. In the past, different techniques have been used for grouping and classifying mosquito pathogens. Except the pathogenicity to mosquito larvae, there are no definitive characters that can separate this from other taxa, therefore the taxonomic status of this group is still unclear.

Here, we have studied variable and hypervariable regions of 16S rRNA gene specific to the strains of Lysinibacillus which correspond to group 1 to 5 of Nakamura [16]. This study was aimed at finding whether the distinctive phenotypic characters, the presence of unique nucleotide sequences and mosquitocidal genes altogether could form basis for distinguishing this group from other spore forming Lysinibacillus.

\section{Materials and Methods}

\section{Source of strains}

The bacterial strains were isolated from soil samples which were collected from various mosquito breeding habitats viz., stagnant ponds, paddy fields and mangrove vegetations at different location in Goa, India [18]. Stock cultures were maintained on NYSM agar slants stored at $4{ }^{\circ} \mathrm{C}$.

Table 1: List of primers used for amplification of toxin genes.

\section{Characterization of the isolates}

Morphological, biochemical and physiological characteristics of the isolates were studied as per Krych et al. [9] and Alexander $\&$ Priest [10].

\section{Amplification of 16S rRNA gene of the isolates}

The genomic DNA was extracted from $24 \mathrm{hrs}$ old culture grown in J-Broth using the method described in Sambrook et al. [19]. Gene of $16 \mathrm{~S}$ rRNA was amplified using the universal primers, a forward primer (S-D-Bact-0011-a-5-17: 5'-GTTTGATCCTGGCTCAG-3`) and a reverse primer (S-*-Univ1392-b-A-15: 5'-ACGGGCGGTGTGTNC-3`). The conditions for PCR amplification were used as described by Prabhu et al. [20]. PCR products were purified using purification kit (Quiagen). Purified PCR product obtained was outsourced to Bangalore Genei for sequencing. The sequences obtained were submitted in the Gene Bank under the accession numbers FJ473362 (KSD1), FJ473363 (KSD-2), FJ473364 (KSD-3), FJ473365 (KSD-4), FJ473368 (KSD-8) and FJ473369 (KSD-7).

The sequences obtained were compared with those available in NCBI database using BLASTn. The sequences from phylogenetic groups described by Nakamura [16] for Bacillus sphaericus like organisms were compared. Clustal X version 2.0.7 was used to generate multiple sequence alignment between these selected sequences. Consensus sequences obtained from these multiple alignment within groups were compared with sequences available in NCBI databases. Consensus sequences for these groups were then analyzed in relation to variable and hypervariable (HV) regions to develop phylogenetic tree using neighbor joining (NJ) method. Tree was obtained with 1000 seeds and 10000 bootstraps. Final tree was rooted and drawn using MEGA4 [21].

\section{PCR amplification of genes encoding the mosquitocidal toxins}

Genomic DNA of isolates was subjected to PCR amplification to detect the presence of genes encoding toxins. Primers used for amplification of toxin genes binA, binB, mtx1, mtx2 and $m t x 3$ are listed in Table 1. Conditions used for amplification were as described in $[6,22,23]$.

\begin{tabular}{|c|c|c|c|c|}
\hline S. No. & Gene & Primer sequence & Expected & References \\
\hline & & & amplicon size & \\
\hline & & & (bp) & \\
\hline \multirow[t]{2}{*}{1} & $\operatorname{bin} A$ & 5'- GTACATTCGCGTTATGG -3(F) & 720 & [23] \\
\hline & & 5'- GTATCATAGGTGAACC -3'(R) & & \\
\hline \multirow[t]{2}{*}{2} & $\operatorname{bin} B$ & 5'- CACGGAATGGTTATGGTT -3’(F) & 1054 & {$[23]$} \\
\hline & & 5'-AGGTGCATTAGGATACGA -3'(R) & & \\
\hline 3 & $m t x 1$ & 5'-CCAGGGGGAATTCGTC -3'(F) & 600 & {$[23]$} \\
\hline
\end{tabular}


Advances in Biotechnology \& Microbiology

\begin{tabular}{|c|c|c|c|c|}
\hline & & 5'- GAGCTACTGTTCTCAC -3'(R) & & \\
\hline \multirow[t]{2}{*}{4} & $m t \times 2$ & 5'- AATGAAAAGGACCAAATTACTTTTTTAT-3'(F) & $800-900$ & [22] \\
\hline & & 5'- TTATTTAAAAGAAATTTCTTTAACATCTATTA - 3'(R) & & \\
\hline \multirow[t]{2}{*}{5} & $m t x 3$ & 5'- ATGAAAAACAAAGCAAAAGTAATATTAATGGGA - 3'(F) & $1100--1200$ & [6] \\
\hline & & 5'-GAGTATGTTTTTTCATCTGTCTACGAA-3'(R) & & \\
\hline
\end{tabular}

\section{Source of immature of test mosquito species}

Culex quinquefasciatus larvae were obtained from the insectary of National Institute of Malaria Research, Field Unit, Goa, where this mosquito species is maintained at a temperature of $27 \pm 2{ }^{\circ} \mathrm{C}$, relative humidity of $70 \pm 5 \%$ and a photoperiod: scotoperiod of 12:12 h (light: dark). From this laboratory bred mosquitoes, 3rd instars larvae were selected and used for larval bioassays to determine larvicidal activity of bacterial strains.

\section{Preparation of Lyophilized powder for Bioassay}

Isolates were grown in a $250 \mathrm{ml}$ conical flask containing $100 \mathrm{ml}$ of NYSM broth and incubated at $30^{\circ} \mathrm{C}$ on a rotary shaker for $96 \mathrm{hrs}$. Spore crystals were harvested by centrifugation at $5000 \mathrm{rpm}$ for $10 \mathrm{~min}$, cell pellet was washed twice with sterilized distilled water and the final pellet was kept for lyophilization which was carried out in Delvac Model (Lyodel) at temperature $-40{ }^{\circ} \mathrm{C}$. Vacuum was applied for 4-6 hours for complete drying. Lyophilized culture was stored at $4{ }^{\circ} \mathrm{C}$ until use.

\section{Larval Bioassays}

Stock dilutions were prepared by dissolving lyophilized powder in sterile distilled water. Dilutions were made to obtain appropriate range of dosage [24]. For each of the doses, 3 replicates of 25 healthy III instar larvae of Culex quinquefasciatus were introduced in $250 \mathrm{ml}$ plastic bowl containing $100 \mathrm{ml}$ of sterile distilled water. Concurrent control was maintained under similar conditions without the addition of spore suspension. The mortality was recorded by counting live larvae after 24 \& 48 hours. LC50 were determined by Probit analysis with SPSS PASW 18.0 indicating mean and standard errors [25].

\section{Results and Discussion}

\section{Phenotypic characterisation of isolates}

Colonies of all six mosquito pathogenic isolates were whitecreamish in colour. The vegetative cells were Gram's positive, long and rod-shaped. Sporulating cells consisted of racket shaped swollen sporangia were containing round endospores associated with the crystal proteins. These isolates did not produce nitrate reductase, amylases, tyrosinase and showed the production of catalase, urease and acid from glucose. All isolates grew in broth with 2 to $7 \% \mathrm{NaCl}$, sensitive to erythromycin and resistant to streptomycin. These isolates cleared adenine and were unable to utilize citrate and L-isoleucine in the medium.

Earlier, mosquito-pathogenic bacterial strains were classified on the basis of limited biochemical tests as Bacillus sphaericus Krych et al. [9] demonstrated using DNA-DNA homology that Bacillus sphaericus actually a conglomerate of 5 homology groups. The mosquito-pathogenic strains belong to subgroup IIA. Non-pathogenic strains belong to subgroup IIB were identified as Bacillus fusiformis. Alexander \& Priest [10] used several phenotypic tests in order to give features specific to mosquito-pathogenic strains belong to subgroup IIA. The above isolates showed all the features in agreement to the described feature of subgroup IIA. It was noted that subgroup IIA pathogens separated from the subgroup IIB non-pathogens only by the ability of the former to clear adenine from nutrient agar and sensitivity to erythromycin. An additional feature is mosquito-pathogenicity, which is based on the production of toxins. Recently, members of group I to IV of Krych et al. [9] were re-designated as members of genus Lysinibacillus due to presence of lysine in the cell wall [17].

\section{Phylogenetic characterization}

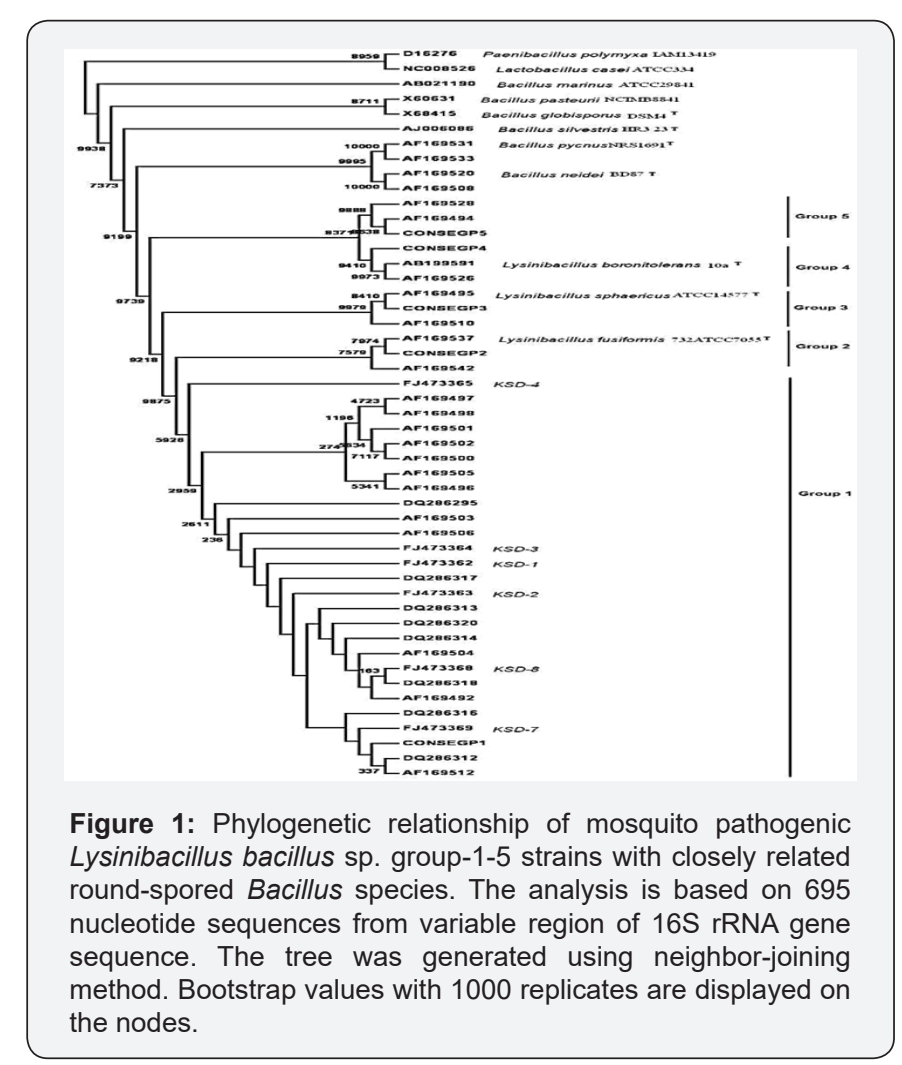

Sequences of 16S rRNA genes obtained from the isolates were used to search NCBI databases using BLASTn which showed high similarity with Lysinibacillus fusiformis and 
Lysinibacillus sphaericus. (Figure 1) presents phylogenetic tree based on comparison of the variable region of $16 \mathrm{~S}$ rRNA sequences generated with that of sequences of species belonging to Lysinibacillus genus, including strains of Bacillus sphaericus like organisms earlier reported as pathogenic to mosquitoes in the GenBank database. Phylogenetic tree separates these organisms into five groups. All the six mosquito-pathogenic isolates were clustered in Group 1 in accordance with Nakamura [16] that correspond to sub-group IIA as described above.
Group 2 and Group 3 of 16S rRNA gene alignments correspond to sub-group IIB and Group I of DNA-DNA homology and were named as Lysinibacillus fusiformis and Lysinibacillus sphaericus, respectively. Group 4 has been named as Lysinibacillus boronitolerans which corresponds to group III of DNA-DNA homology [26]. So far Group 1 containing mosquito pathogenic strains and Group 5 (DNA-DNA homology Group IV) has not been recognised as a separate species.

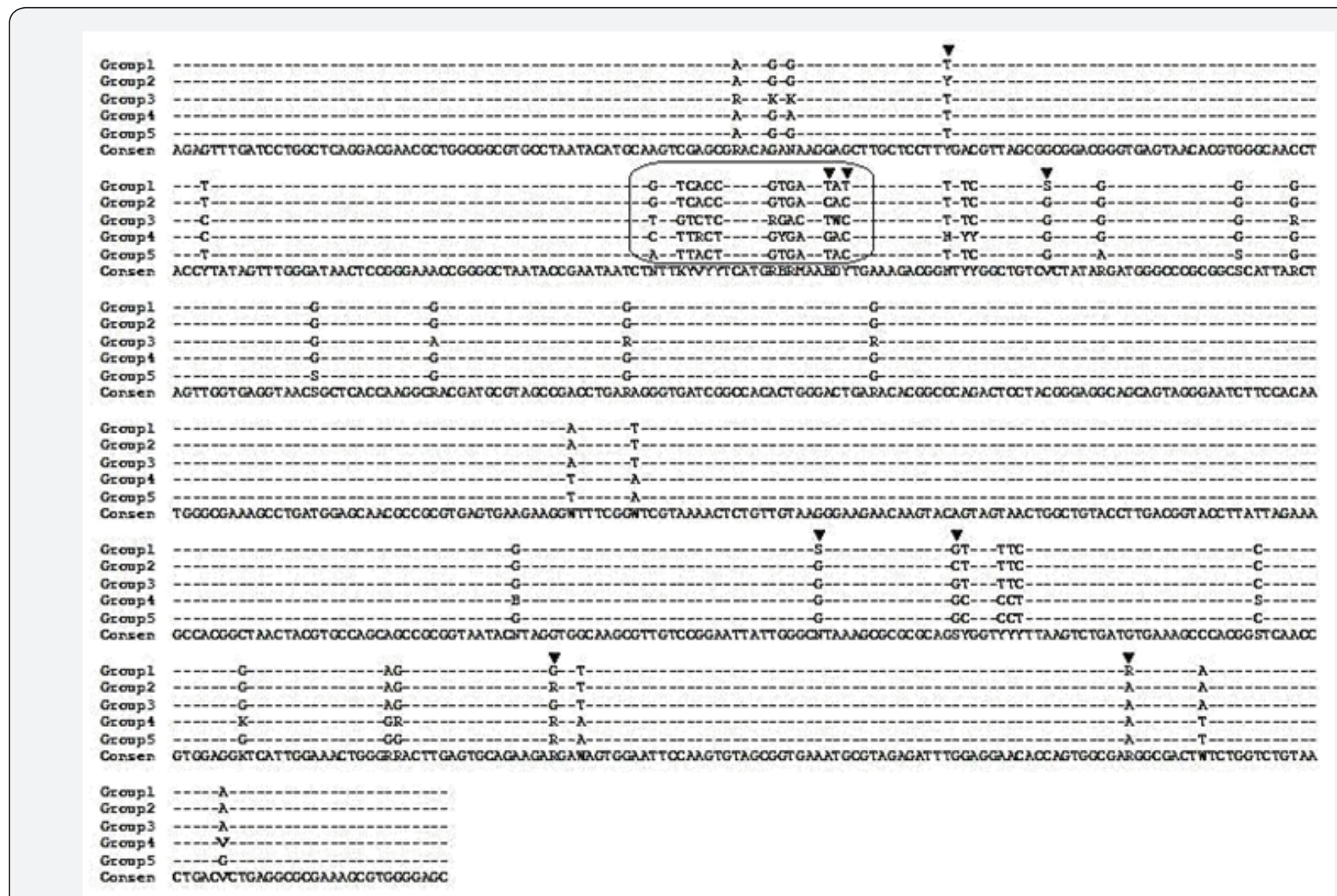

Figure2: Consensus nucleotide sequence derived based on the result of multiple sequence alignment of 780 bp sequences of 165 rDNA from five groups of Bacillus sphaericus like organisms [16]. Dashes indicate conserved nucleotide, Nonconserved nucleotides were represented in bold, Arrows indicates distinctive nucleotide sites between group 1 and group 2 Lysinibacillus bacillus species. Box indicates hypervariable regions.

Consensus sequences derived in this study for five groups of Lysinibacillus are shown in (Figure 2). A variable region (V) of 695 bp nucleotide position stretching from 62 to 756 bps and a hypervariable (HV) region of $22 \mathrm{bps}$ at nucleotide position from 178 to 199 bps were found among all these five groups. The HV regions were conserved and specific to respective groups. Interestingly, the highly conserved HV region in Group 1 and Group 2 were different only by three nucleotides at position 197 199 bps. Additionally, we found six single nucleotide differences in the variable regions of Group 1 and 2 which were used to differentiate members of these groups. These unique nucleotide differences among these two groups are at nucleotide position $85,221,571,586,665$ and 720.
The phylogenetic tree shown in (Figure 1) included the consensus sequences drawn for five groups. Sequence similarities of the above mentioned variable region between these five groups are shown in (Table 2). This analysis reveals that Group 1 and Group 2 have maximum commonalities of only $98 \%$. Our findings showed that variable region was sufficient in distinguishing the five groups as the nodes were showing very high bootstrap values (Figure 1). These findings match with the phylogenetic tree drawn using 16S rDNA sequences more than 1400 bases [16]. Although, HV regions showed the signature sequences of Group 1 and Group 2 but were incapable of separating these groups on its own during phylogenetic analysis. This region was earlier used by de Muro et al. [12] for designing probe for identifying the mosquito-pathogenic isolates. 
Table 2: Percentage (\%) nucleotide similarity within variable region between five groups of Lysinibacillus species.

\begin{tabular}{|l|c|c|c|c|c|}
\hline & Group-1 & Group-2 & Group-3 & Group-4 & Group-5 \\
\hline Group-1 & 100 & & & & \\
\hline & & & & & \\
\hline Group-2 & 98 & 100 & & & \\
\hline & & & & & \\
\hline Group-3 & 97 & 97 & 100 & & \\
\hline & & & & & \\
\hline Group-4 & 95 & 96 & 95 & 100 & \\
\hline & & & & & \\
\hline Group-5 & 97 & 97 & 96 & 97 & 100 \\
\hline
\end{tabular}

\section{Mosquito-pathogenicity of isolates}

Table 3: Biochemical characteristics of five groups of Bacillus sphaericus like organisms.

\begin{tabular}{|c|c|c|c|c|c|}
\hline & Group1 & Group2* & Group3* & Group4* & Group5* \\
\hline & (IIA) & (IIB) & (I) & (III) & (IV) \\
\hline $\begin{array}{l}\text { Growth on } \\
\text { BATS }\end{array}$ & + & + & - & - & V \\
\hline $\begin{array}{c}\text { Sensitivity } \\
\text { to }\end{array}$ & - & - & - & + & - \\
\hline \multicolumn{6}{|l|}{$\begin{array}{c}\text { Strepto- } \\
\text { mycin }\end{array}$} \\
\hline $\begin{array}{c}\text { Sensitivity } \\
\text { to }\end{array}$ & + & - & V & + & + \\
\hline \multicolumn{6}{|l|}{$\begin{array}{l}\text { Erythro- } \\
\text { mycin }\end{array}$} \\
\hline $\begin{array}{l}\text { Utilization } \\
\text { of Citrate }\end{array}$ & - & - & + & V & V \\
\hline $\begin{array}{c}\text { Growth at } \\
7 \% \mathrm{Nacl}\end{array}$ & + & + & - & V & V \\
\hline $\begin{array}{c}\text { Urease } \\
\text { production }\end{array}$ & + & + & - & V & V \\
\hline $\begin{array}{c}\text { Utilization } \\
\text { of }\end{array}$ & - & - & + & V & V \\
\hline \multicolumn{6}{|l|}{ L-isoleucine } \\
\hline $\begin{array}{c}\text { Degradation } \\
\text { of Adenine }\end{array}$ & + & - & - & - & - \\
\hline
\end{tabular}

+, positive; -, negative; $\mathrm{V}$, variable;

*Data from other study as follows: Group2, Group3, Group4 and Group5 organism's biochemical characteristics as described in Alexander\& Priest [10].

All 6 isolates were tested against laboratory reared III instar larvae of Culex quinquefasciatus. These isolates were found highly toxic to Culex quinquefasciatus larvae, with LC50 values ranging from 0.05 to $0.87 \mathrm{ppm}$ at $24 \mathrm{hrs}$ post treatment and 0.018 to $0.58 \mathrm{ppm}$ at $48 \mathrm{hrs}$ (Table 3). Isolate KSD-2 had lowest LC50 value of $0.05 \& 0.018 \mathrm{ppm}$ at 24 and $48 \mathrm{hrs}$ respectively and hence was most lethal. Lethal conc. of KSD-2 was 32 folds lower as compared with commercial Bacillus sphaericus 101 (H5a5b) at $48 \mathrm{hrs}$ post treatment. Except KSD-1, all other isolates were 2 to 32 fold more toxic than commercial strain.

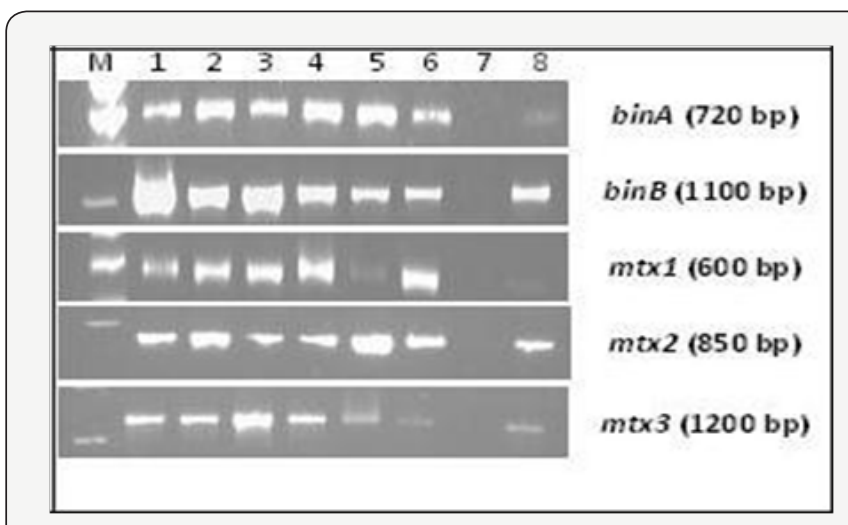

Figure3: PCR amplification of binary and mosquitocidal toxin genes. Lane M: DNA ladder; Lane1: KSD1; Lane2: KSD 2; Lane3: KSD 3; Lane4: KSD4; Lane5: KSD 7; Lane6: KSD 8; Lane7: - ve control; Lane 8: Bacillus sphaericus 101 (H5a5b) reference strain.

PCR amplification of binary and mosquitocidal genes confirmed the presence of binA, binB, $\mathrm{mtx} 1, \mathrm{mtx} 2$ and $\mathrm{mtx} 3$ in all 6 isolates as shown in (Figure 3). Larvicidal activity was found to be primarily associated with binary toxins. This could be explained as only sporulating stage was tested for determination of larvicidal activity. Previous studies also showed that highly toxic strains are known to produce both binary and Mtx toxin proteins, while other strains synthesize either of these toxins [8]. The DNA sequences of the genes encoding these proteins are highly homologous between the strains, although they were isolated from different continents [27]. Previously, pathogenicity of Bacilli was considered important for distinguishing taxa as there were no reliable phenotypic characters [10], but now probe based on 16S rRNA and toxin genes are available to segregate mosquito-pathogenic strains morphologically similar to Bacillus sphaericus like organisms $[12,28]$. In the present study, the presence of both bin and mtx genes in the mosquitopathogenic strains has been confirmed.

\section{Proposal for species novo}

Classical characterization methods for describing Bacillus sphaericus have failed to provide enough taxonomic information [29]. Krych et al. [9] were the first to identify 5 distinct DNA-DNA homology groups among the 50 strains, which include 7 strains showing pathogenicity to mosquito larvae, which were placed in the sub-Group IIA. There was about $62 \%$ DNA-DNA sequence homology, with $\Delta \mathrm{Tm}$ of about $7^{\circ} \mathrm{C}$ between the strains of subgroup IIA and IIB. It is generally argued that strains within a species show greater than $70 \%$ DNA sequence homology and thermal hybrid stability $(\Delta \mathrm{Tm})$ of less than $6^{\circ} \mathrm{C}[30]$. This amply suggested that sub-group IIA and IIB cannot be allocated to the same species. The creation of a separate species for the mosquito pathogens was contemplated earlier but due to lack of positive phenotypic tests, other than mosquito pathogenicity, its identification as a taxon has been delayed. Alexander \& 
Priest [10] used several phenotypic tests and tried to develop numerical taxonomic group in order to identify features specific to mosquito-pathogenic strains belonging to subgroup IIA. Further support for distinction of sub-group IIA pathogens from non-pathogenic sub-group IIB became possible by rRNA gene pattern [11], RAPD finger print and isoenzyme analysis [31].

These studies revealed a very low similarity between the two subgroups and led to the conclusion that the pathogenic strains are an independent lineage distinct from the other round spore forming bacilli of sub-group IIB. Nakamura [16] attempted to raise the status of sub-group IIA and sub-group IIB to independent groups namely Group 1 and Group 2, respectively using $16 \mathrm{~S}$ rRNA sequences. Now with re-designation of the genus due to presence of Lysine in cell wall the sub-group IIB is known as Lysinibacillus fusiformis.

Table 4: Larvicidal activity of Lysinibacillus species group-1 isolates against III instar larvae of Culex quinquefasciatus.

\begin{tabular}{|c|c|c|c|c|c|}
\hline Time & Strain & $\mathrm{LC}_{50}(\mathrm{ppm})$ & Slope (B) & Intercept & $\mathbf{R} 2$ \\
\hline \multirow[t]{12}{*}{$24 \mathrm{hrs}$} & KSD-1 & $0.87(0.736-1.031)$ & $1.90 \pm 0.14$ & $0.11 \pm 0.06$ & 0.957 \\
\hline & KSD-2 & $0.05(0.035-0.066)$ & $1.17 \pm 0.10$ & $1.53 \pm 0.11$ & 0.935 \\
\hline & KSD-3 & $0.24(0.188-0.301)$ & $1.55 \pm 0.14$ & $0.95 \pm 0.09$ & 0.999 \\
\hline & KSD-4 & $0.08(0.061-0.107)$ & $1.15 \pm 0.10$ & $1.20 \pm 0.10$ & 0.966 \\
\hline & KSD-7 & $0.14(0.109-0.178)$ & $1.62 \pm 0.14$ & $1.37 \pm 0.12$ & 0.997 \\
\hline & KSD-8 & $0.33(0.249-0.430)$ & $1.20 \pm 0.10$ & $0.57 \pm 0.07$ & 0.980 \\
\hline & Bacillus & $0.67(0.535-0.853)$ & $1.34 \pm 0.12$ & $0.23 \pm 0.07$ & 0.995 \\
\hline & sphaericus & & & & \\
\hline & 101(H5a5b) & & & & \\
\hline & KSD-1 & $0.58(0.474-0.703)$ & $1.66 \pm 0.1$ & $0.39 \pm 0.06$ & 1.000 \\
\hline & KSD-2 & $0.018(0.009-0.028)$ & $1.01 \pm 0.12$ & $1.78 \pm 0.14$ & 0.996 \\
\hline & KSD-3 & $0.13(0.093-0.179)$ & $1.40 \pm 0.10$ & $1.21 \pm 0.11$ & 0.999 \\
\hline \multirow[t]{6}{*}{$48 \mathrm{hrs}$} & KSD-4 & $0.03(0.021-0.044)$ & $1.14 \pm 0.10$ & $1.70 \pm 0.13$ & 0.995 \\
\hline & KSD-7 & $0.08(0.060-0.113)$ & $1.40 \pm 0.14$ & $1.50 \pm 0.13$ & 0.996 \\
\hline & KSD-8 & $0.15(0.104-0.209)$ & $1.06 \pm 0.10$ & $0.86 \pm 0.08$ & 0.998 \\
\hline & Bacillus & $0.32(0.240-0.477)$ & $1.20 \pm 0.12$ & $0.59 \pm 0.07$ & 0.963 \\
\hline & sphaericus & & & & \\
\hline & 101(H5a5b) & & & & \\
\hline
\end{tabular}

PROBIT model: $\mathrm{PROBIT}(\mathrm{p})=$ Intercept $+\mathrm{BX}($ Covariates $\mathrm{X}($ dose $)$ are transformed using the base 10.000 logarithm)

Acknowledgement

We thank the Indian Council of Medical Research, National Institute of Malaria Research, New Delhi for institutional support. We are thankful to the field and laboratory staff of National Institute of Malaria Research (ICMR), Field Unit, Goa, India. The authors also thank Dr. Barbuddhe of ICAR, Research Complex, Goa for providing the Lyophiliser facility. This paper bears the NIMR publication screening committee approval no. $049 / 2016$.
The present investigation clearly identified the differences of 16S rRNA sequences between various members of Lysininbacillus including Lysinibacillus fusiformis and group IIA containing mosquito pathogenic isolates. The phylogenetic tree constructed by taking only variable region was also stable at its nodes with high value of bootstrap. The distinct features specific to each of the species of Lysinibacillus are listed in (Table 4). These taxonomic signatures could be reliably utilized for the screening and identification of mosquito pathogenic strains. Due to the taxonomic value of the unique sequences observed based on variable region in the mosquito-pathogenic strains and phenotypic characters, we propose to designate mosquitopathogenic strains as a new species Lysinibacillus kychi sp. novo that are hitherto clustered in Group IIA by Krych et al. [9] and Group 1 by Nakamura [16]. 
4. Thanabalu T, Hindley J, Jackson Yap J, Berry C (1991) Cloning, sequencing, and expression of a gene encoding a 100-kilodalton mosquitocidal toxin from Bacillus sphaericus SSII-1. J Bacteriol 173(9): 2776-2785.

5. Thanabalu T, Porter AG (1996) A Bacillus sphaericus gene encoding a novel type of mosquitocidal toxin of $31.8 \mathrm{kDa}$. Gene 170(1): 85-89.

6. Liu JW, Porter AG, Wee BY, Thanabalu T (1996) New gene from nine Bacillus sphaericus strains encoding highly conserved 35.8-kilodalton mosquitocidal toxin. Appl Environ Microbiol 62(6): 2174- 2176.

7. Yang YL, Wang A, Gaviria Z, Berry C (2007) Proteolytic stability of insecticidal toxins expressed in recombinant Bacilli. Appl Environ Microbiol 73(1): 218-225.

8. Liu JW, Hindley WJ, Porter AG, Priest FG (1993) New high-toxicity mosquitocidal strains of Bacillus sphaericus lacking a 100-kilodalton toxin gene. Appl Environ Microbiol 59(10): 3470-3473.

9. Krych VK, Johnson JL, Yousten AA (1980) Deoxyribonucleic Acid Homologies among Strains of Bacillus sphaericus. Int J Syst Bacteriol 30(2): 476-484.

10. Alexander B, Priest FG (1990) Numerical classification and identification of Bacillus sphaericus including some strains pathogenic for mosquito larvae. J Gen Microbiol 136(2): 367-376.

11. Aquino de Muro M, Mitchell WJ, Priest FG (1992) Differentiation of mosquito-pathogenic strains of Bacillus sphaericus from non-toxic varieties by ribosomal RNA gene restriction patterns. J Gen Microbiol 138(6): 1159-1166

12. Aquino de Muro M, Priest FG (1993) Phylogenetic analysis of Bacillus sphaericus and development of an ologonucleotide probe specific for mosquito-pathogenic strains. FEMS Microbiol lett 112(2): 205-210.

13. Jahnz U , Fitch A, Priest F G (1996) Evaluation of an rRNA-targeted oligonucleotide probe for the detection of mosquitocidal strains of Bacillus sphaericus in soils: characterization of novel strains lacking toxin genes. FEMS Microbiol Eco 20(2): 91-99.

14. Woodburn M, Yousten A, Hilu K (1995) Random amplified polymorphic DNA fingerprinting of mosquito pathogenic and non-pathogenic strains of Bacillus sphaericus. Int J Syst Bacteriol 45(2): 212-217.

15. Miteva V, Pobell SS (1999) Random and repetitive primer amplified polymorphic DNA analysis of Bacillus sphaericus. J Appl Microbiol 86(6): 928-936.

16. Nakamura LK (2000) Phylogeny of Bacillus sphaericus-like organisms. Int J syst and Evol Micribiol 50(Pt 5): 1715-1722.

17. Ahmed I, Yokota A, Yamazoe A, Fujiwara T (2007) Proposal of Lysinibacillus boronitolerans gen.nov.sp. nov., and transfer of Bacillus fusiformis to Lysinibacillus fusiformis comb. nov. and Bacillus sphaericus to Lysinibacillus sphaericus comb. nov. Int J syst and Evol Microbiol 57(pt 5): 1117-1125.
18. Dhindsa KS, Sangodkar UMX, Kumar A (2002) Novel Cost-effective method of screening soils for the presence of mosquito-pathogenic bacilli. Lett Appl Microbiol 35(6): 457-461.

19. Sambrook J, Maniatis T, Fritsch EF (1989) Molecular cloning: a laboratory manual. ( $2^{\text {nd }}$ edn), Cold Spring Harbor Laboratory Press, New York, USA, pp. 1546.

20. Prabhu NN, Santimano MC, Mavinkurve S, Bhosle SN, Garg S (2010) Native granule associated short chain length polyhydroxyalkanoate synthase from a marine derived Bacillus sp. NQ-11/A2. Antonie van Leeuwenhoek 97(1): 41-50.

21. Tamura K, Dudley J, Nei M, Kumar S (2007) MEGA4: molecular evolutionary genetics analysis (MEGA) software version 4.0. Mol Biol Evol 24(8): 1596-1599.

22. Chan SW, Thanabalu T, Wee BY, Porter AG (1996) Unusual Amino Acid Determinants of Host Range in the Mtx2 Family of Mosquitocidal Toxins. J Biol Chem 271(24): 14183-14187.

23. Otsuki K, Guaycurus TV, Vicente ACP (1997) Bacillus sphaericus entomocidal potential determined by polymerase chain reaction. Mem Inst Oswaldo Cruz 92(1): 107-108.

24. Sieo CC, Wong BT, Abdullah N, Ho YW ( 2007) Effects of extraction methods and age of cells on the whole-cell protein patterns of Lactobacillus. Res J Microbiol 2(10): 727-734.

25. Finney DJ (1971) Probit analysis-a statistical treatment of the sigmoid response curve, ( $3^{\text {rd }}$ edn) Cambridge: Cambridge University Press, UK, pp. 333.

26. Carboulec N, Priest FG (1989) Phenotypic characterization of some strains of Bacillus sphaericus. Lett Appl Microbia 9(3): 113-116.

27. Berry C, Jackson-Tap J, Oei C, Hindley J (1989) Nucleotide sequence of two toxin genes from Bacillus sphaericus MAB59: sequence comparisons between five highly toxinogenic strains. Nucleic Acids Research 17(18): 7516.

28. Aquino de Muro M, Priest F G. (1994) A colony hybridization procedure for the identification of mosquitocida 1 strains of Bacillus sphaericus on isolation plates. J Invert Pathol 63(3): 310-313.

29. Gordon RE, Haynes WC, Pang C H-N (1973) "The Genus Bacillus." United States Department of Agriculture, Washington, DC, pp. 427

30. Grimont F, Grimont PAD (1991) DNA fingerprinting. In Nucleic Acid Techniques in Bacterial Systematics, Edited by E. Stackebrdndt \& M Goodfellow (Eds.), Chichester: John Wiley. pp. 249-219.

31.Zahner V, Rabinovitch L, Cavados CFG, Momen H (1994) Multilocus enzyme electrophoresis on agarose gel as an aid to the identification of entomopathogenic Bacillus sphaericus. J Appl Bacterial 76(4): 327335 .

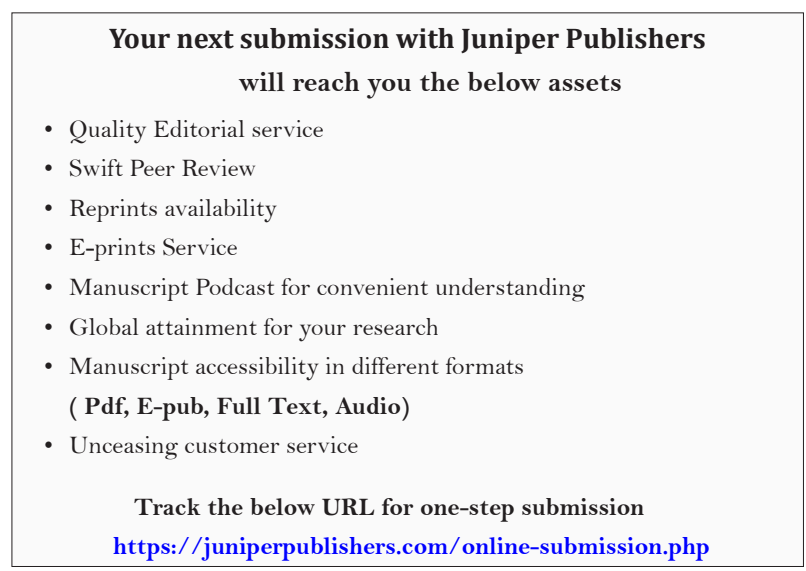

